\section{Список Аитературы}

1. Масюкова С. А., ГАадько В.В., Устинов М.В. и Ар. Бактериальные инфекции кожи и их значение в кАинической практике Аермато1ora // Consilium medicum. 2004. - Tом 6. № 3.- C. 180-185.

2. Белоусова Т. А., Горячкина М.В. Алгоритм наружной терапии Аерматозов сочетанной этиологии. Вест Аерматол и венерол. 2011; 5: 138-144.

3. Новиков А. И., Аогинова Э. А. Болезни кожи инфекционного и паразитарного происхожАения. РуковоАство А^я врачей. М.: МеАицинская книга, 2001.-283 С.

4. Европейское руководство по лечению АерматологическиХ заболеваний (ПоА РеА. А.А. Кацамбаса, Т.М. Аотти). ИзА-во МЕАпресс-информ.-2009.-736 с.

5. Короткий Н.Г. Тихомиров А. А. Гамаюнов Б.Н. Сравнительная эорорективность Момата (мометазона фороата) и гилрокортизона 17-бутирата в наружной терапии атопического Аерматита у Аетей. Русский медицинский жернал. - 2008. С. $1183-1186$.

6. Томимова А.Ю. Торшхоева Р.М. Геворкян А. К Вознесенская Н.И. Эорорективность и безопасность применения мометазона фруроата при атопическом Аерматите у Аетей // Пф. 2009. № 4.- С. 12-16.

7. Фелеральные клинические рекомендации по ведению больных пиодермиями. - Москва. $-2015-28$ с

8. Gual A, Pau-Charles I, Abeck D. Topical Corticosteroids in Dermatology: From Chemical Development to Galenic Innovation and Therapeutic Trends. 2015; J Clin Exp Dermatol Res 6: 269-72.
9. Chi C. C. et al. Updated evidence-based (S2e) European Dermatology Forum guideline on topical corticosteroids in pregnancy. JEADV 2017; 31: 761-773.

10. Белькова Ю.А. Фармакоэпилемиологические имикробиологические аспекты оптимизации лечения иноеекций кожи и мягких тканей в ам булаторныхусловиях. Смоленск.-2004.-Автореср. Аисс. канА. МеА. наук.-24 с.

11. Koning S, van der Sande R, Verhagen AP. Interventions for impetigo. Cochrane Database Syst Rev. 2012 Jan 18; 1: CD003261.

12. Кениксфрест Ю.В. и соавт. Анализ ретроспективных $а$ анных результатов микробиологического обслеАования больных атопическим Аерматитом». Consilium Medicum. Аерматология. 2016; 1: 14-19.

13. Das M. C. Biswas A. Screening Antimicrobia Susceptibility of Gentamicin, Vancomycin, Azithromycin, Chloramphenicol and Cefotaxime Against Selected Gram Positive and Gram Negative Bacteria International Journal of Pharma Research and Health Sciences. 2014; (4): 324-331.

14. Moorhouse E., Fenelon L., Hone R., et al. Staphylococcus aureus sensitivity to various antibiotics a nationa survey in Ireland 1993. Ir J Med Sci. 1996; 65 (1): 40-43.

5. Силоренко С. В. Резван С.П. Грудинина С. А. и Ар. Результаты многоцентрового исслеАОвания чувствительности стафииококКов К антибиотикам в Москве и Санкт-Петербурге. Антибиотикиихимиотерапия. 1998. - № 43.-С. 7-25.

16. Страчунский ^.С. и соавт. КАиническая микробиология и антимикробная химиотерапия. 2002; 2 (4): 157-163.

17. Kareivienè V. Pavilonis, G. Sinkute, S. Liegiute G. Gailiene Staphylococcus aureus resistance to antibiotics and spread of phage types Medicina (Kaunas), 42 (2006), pp. 332-339.
18. Bernard P. et al. Antibiotic susceptibility of Staphylococcus aureus strains responsible for community-acquired skin infections. Ann Dermatol Venereol. 2008 Jan; 135 (1): 13-9.

19. Yılmaz E. S. Aslantas Ö. Antimicrobial resistance and underlying mechanisms in Staphylococcus aureus isolates. Asian Pacific Journal of Tropical Medicine 2017; 10 (11): 1059-1064.

20. Сергеев А.Ю. илр. Аоказательный опыт терапии Аерматомикозов сертаконазолом // Иммунопатология, амергология, иноректология.2015.-T. 4.- C. 98-110.

21. Richter S. S., Rudolph P. Galask R.P., Mess er S. A. Antifungal Susceptibilities of Candida Species Causing Vulvovaginitis and Epidemiology of Recurrent Cases. Journal of Clinical Microbiology, May 2005, p. 2155-2162.

22. Mahmoudabadi A. Z. Antifungal Susceptibility of Candida Species Isolated From Candiduria. Jundishapur Journal of Microbiology 6 (1): 24-28.

23. Choukri F., Benderdouche M., Sednaoui P. In vitro susceptibility profile of 200 recent clinical isolates of Candida spp. to topical antifungal treatments of vulvovaginal candidiasis, the imidazoles and nystatin agents. Journal de Mycologie Médicale.-2014. Volume 24, Issue 4, P. 303-307.

24. Abastabar M., Shokohi T., Rouhi Kord R. In vitro activity of econazole in comparison with three common antifungal agents against clinical Candida strains isolated from superficial infections. Curr Med Mycol. 2015 Dec; 1 (4): 7-12.

25. Ebner F., Heller A, Rippke F, Tausch I. Topical use of dexpanthenol in skin disorders. Am J Clin Dermatol. 2002; 3 (6): 427-33.

26. Proksch E. et al. Topical use of dexpanthenol: a 70th anniversary article. Journal of Dermatological Treatment, 2017; 28 (8): 766-773.

Аля цитирования. Круглова А.С., Федоров А. В., Стенько А.Г., Грязева Н. В., Яковлев А. Б. Актуальные рекоменАации по применению много-

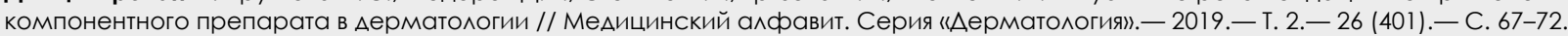

\title{
Принципы диагностики
}

\section{и терапии аногенительного зуда у женщин}

\author{
Ю.Н. Перламутров, А.м.н., профр., зав. кафрелрой, заслуженный врач России \\ Т.В. Василенко, К.М.Н., АОцент \\ К. Б. О^ьховская, К.М.Н., АОценТ
}

KadpeАpa кожных и венерических болезней ФГБОУ ВО «Московский госуАарственный меАикостоматологический университет имени А.И. ЕвАокимова» МинзАрава России, г. Москва

\section{Principles of diagnostics and therapy of anogenital pruritus in women}

Yu. N. Perlamutrov, T.V. Vasilenko, K. B. Olkhovskaia

Moscow State University of Medicine and Dentistry n.a. A.I. Evdokimov, Moscow, Russia

Резюме

ЗуА аногенитальной области является серьезной проблемой преимущественно женщин в тот ими иной периоА жизни. Мультифакториальность Аерматозов с Аокализацией в области вульвы и ануса, отсутствие изученности патофизиологии зуАа в принципе опреАеляют Аанную проблему как актуальную. ПровеАение рациональной Аифференциальной Аиагностики и использование современных среАств, способных быстро купировать симптом, позволяют повысить эффективность специализированной меАицинской помощи Аанной катеГории больных. КАючевые Слова: аногентальный зуА, этиология, патофизиология, Аифференциальная Аиагностика, терапия.
Summary

Anogenital itching is a serious problem for most women at one or another period of life. The multifactorial nature of dermatoses with localization in the vulva and anus, the lack of knowledge of the pathophysiology of itching, in principle, determine the problem of itching in the genital area as a relevant medical problem. Conducting a rational differential diagnosis and the use of modern treatment that can quickly jugulate a symptom will at the present stage increase the effectiveness of specialized medical care for this category of patients.

Key words: anogenital pruritus, etiology, pathophysiology, differential diagnosis, therapy. 


\section{Введение}

Заболевания вульвы относятся к междисциплинарной патологии, решением вопроса которых занимаются врачи различных специальностей: дерматовенерологи, гинекологи, урологи и проктологи. Заболевания аногенитальной области у женщин различны по этиологии и патогенезу, часто сопровождаются выраженной клинической симптоматикой. Одним из самых распространенных симптомов является зуд [1].

Определение зуда был сформулировано более 340 лет назад немецким врачом С. Хафенреффером (S. Hafenreffer): «неприятное ощущение, вызывающее осознанное и рефлекторное желание почесать зудящее место». На основании нейропатофизиологии зуд подразделяют на зуд с первичным поражением кожи (дерматозы), зуд без первичного поражения кожи (системная и неврологическая патология, психические отклонения), зуд с вторичным поражением кожи (дерматозы, системная и неврологическая патология, психические отклонения) [2]. Зуд может возникать остро или протекать в хронической форме (продолжительность более 6 недель), носить распространенный или локальный характер. Кроме того, зуд может возникнуть в результате сосуществования нескольких заболеваний или быть неопределенного происхождения [3].

Аногенитальный зуд определяется как зуд, локализующийся в области заднего прохода, перианальной области и кожи гениталий. Анальный зуд регистрируется у $1-5 \%$ взрослого населения и чаще встречается у мужчин, чем у женщин. Частота возникновения зуда вульвы неизвестна, но очевидно, что большинство женщин страдают им в какой-то момент своей жизни, чаще всего в постменопаузе в результате дефицита эстродиола, когда зуд является основным симптомом дистрофии слизистой вульвы. Аногенитальный зуд у женщин является причиной тяжелого и выраженного нарушения качества жизни, преимущественно за счет нарушения сна, так как такой тип зуда увеличивается к вечеру и выраженно беспокоит в ночное время суток. Хронический зуд аногенитальной области в большей степени, чем боль, может влиять на общее состояние пациенток и в экстремальных случаях привести к угрозе возникновения суицидальных мыслей и действий [4-6].

\section{Этиология аногенитального зуда у женщин}

Выделяется множество причин развития зуда вульвы и перианальной области. Аногенитальный зуд может быть проявлением как заболеваний кожи и слизистых оболочек, так и системной патологии. Острый аногенитальный зуд преимущественно обусловлен инфекциями урогенитального тракта или развитием простого или аллергического контактного дерматита. Хронический аногенитальный зуд обусловлен папулосквамозными заболеваниями вульвы, первичными воспалительными процессами гениталий, механическим раздражением, злокачественными новообразованиями и (или) может носить психогенный характер [7]. Аногенитальный зуд может быть проявлением: системных заболеваний - сахарного диабета, заболеваний печени, лейкемии, лимфомы, почечной недостаточности, железодефицитной анемии, расстройств соединительной ткани, гипертиреоза, гиповитаминоза и целиакии [8]; патологии аноректальной области - геморроя, анальной трещины, свища, выпадения прямой кишки, анальных папиллом, абсцессов и болезни Крона; опухолевых процессов - себорейного кератоза, ангиокератомы и бовеноидного папулеза; лекарственных реакций; беременности; травм - бритья, ожогов, введения инородных тел; фекальных загрязнений; пищевых приверженностей - употребления кофе, чая, колы, алкоголя, шоколада, помидоров, молока, арахиса, цитрусовых и специй; пояснично-крестцовой радикулопатии [9].

\section{Патофизиология зуда}

Несмотря на достижения современной науки, патофизиология зуда не изучена, что обусловлено субъективной природой симптома, отсутствием специфических нейрофизиологических и молекулярных моделей на животных и ограниченным представлением о медиаторах и индукторах зуда. Гипотезы механизмов развития зуда были сформулированы на основании исследования патофизиологии боли [10].

Наиболее значимыми медиаторами зуда считаются гистамин, ацетилхолин, субстанция Р, пептид, связанный с генами кальцитонина (CGRP), опиоидные пептиды, протеазы, брадикинин, серотонин, фактор активации тромбоцитов, нейротрофины, простагландин Е и некоторые цитокины (IL-2, IL-6, IL-31, ФНО- $\alpha$ и - $\beta$, эозинофильные белки) [11].

Считается, что ощущение зуда и боли является результатом активации сети свободных нервных окончаний С-волокон в эпидермисе. Предполагается, что нервный импульс, который вызывает появление ощущения зуда, передается по той же нейронной связи, что и болевые импульсы: от периферических нервных окончаний в дорсальные рога спинного мозга, через переднюю комиссуру, по спиноталамическому тракту к контралатеральному ламинарному ядру таламуса. Полагают, что таламокортикальный тракт третичных нейронов выступает в качестве «реле» для передачи импульса посредством интеграции ретикулярной активирующей системы таламуса в нескольких областях головного мозга. В ответ возникает желание расчесывать кожу. После почесывания кожный зуд вновь возникает спустя 15-25 минут. Однако в ряде случаев, особенно у пациентов с хроническими дерматозами, ощущение зуда после расчесывания не прекращается, что приводит к экскориации [12].

Механизм, посредством которого зуд купируется при расчесывании, достоверно не установлен. Есть предположение, что травматизация кожи приводит к гибели нервных окончаний, которые располагаются поверхностно, и это способствует снижению передачи импульсов. Также, возможно, во время расче- 
сывания формируются сенсорные импульсы, прерывающие нервную дугу, ответственную за возникновение ощущения. Кроме расчесывания, уменьшить зуд помогают вибрации, уколы в зудящую область, воздействие тепла, холода, ультрафиолетового излучения [13]

\section{Обследование пациенток \\ с аногенитальным зудом}

Пациентки с аногенитальным зудом представляют сложную дифференциально-диагностическую проблему. Зуд данной области может быть результатом воздействия одного или чаще нескольких разнонаправленных факторов, выделить которые из большого перечня раздражителей крайне тяжело. В свою очередь хроническое течение зуда аногенитальной области обусловливает формирование серьезного психологического и социального дискомфорта для каждой женщины, в результате чего теряется вера в выздоровление, снижается обращаемость пациенток к специалистам, формируются предпосылки к формированию нервно-психического напряжения, и зуд приобретает черты психогенного. Результаты психофизической травмы вульвы и перианальной области искажают клиническую картину, осложняя диагностический поиск. При длительном течении зуда клинические признаки патологии вульвы могут усугубляться, изменяться или маскироваться вторичной бактериальной или грибковой инфекцией вследствие расчесов или неправильного лечения (использование бензокаина, сульфониламидов, ртутных антисептиков, антибиотиков и фунгицидных средств). Кроме того, клинический осмотр может выявить заболевание, которое способствовало возникновению, или, чаще, он позволяет только констатировать вторичное поражение аногенитальной области вследствие расчесов или химического воздействия веществ, которые женщины используют для подавление зуда. Вследствие этого определить первичные характеристики заболеваний аногенитальной области крайне затруднительно [14, 15].
Регистрация данных анамнеза пациенток с жалобами на зуд в области вульвы или ануса должна включать время появления симптома, его интенсивность (визуальная шкала симптомов [ВАШ]) и качество (суточный ритм), факторы, способствующие облегчению или обострению, реакцию на контакт с водой и предшествующее лечение, историю контакта с зудящими пациентами, животными, характеристику половых контактов, а также реакцию на менструацию и половой акт. Важно определить методы контрацепции, которые применяет женщина, характеристику ежедневных гигиенических мероприятий, историю путешествий, выявить возможные раздражители и аллергены, наличие системной патологии, в частности атопические заболевания и сахарный диабет, а также сопутствующую терапию [16].

Физикальное обследование должно быть в первую очередь сосредоточено на коже и слизистых оболочках половых органов, однако следует уделить внимание исследованию других систем: лимфатических узлов и аноректума, чтобы исключить их вовлеченность. Для установления диагноза необходимо провести дерматологическое обследование для выявления первичных и вторичных повреждений кожи, возникающих в результате расчесов (экскориация, гиперпигментация и лихенизация), характера и наличия генитальных и аноректальных выделений. Лабораторное обследование может не быть обязательным при первом посещении пациенток с первичными высыпаниями, но должно проводиться в обязательном порядке, если выявляются признаки или симптомы болезней внутренних органов. Лабораторный и инструментальный скрининг должен включать клинический анализ крови и мочи, тест на определение функции щитовидной железы, содержание глюкозы в крови, уровень мочевины, креатинина, печеночных ферментов, исследование кала, рентген грудной клетки, УЗИ брюшной полости и онкологический поиск, соответствующий возрасту. Дополнительно могут быть проведены дерматоскопия кожи для исключения наличия чесоточных ходов, КОН-микроскопия на предмет обнаружения патогенного грибка, тесты для выявления аллергенов, биопсия кожи и слизистых оболочек [16].

Клиническая дифференциальная диагностика проводится между заболеваниями, которые чаще всего сопровождаются зудом данной локализации: аллергический и простой контактный дерматит, экзема, атопический дерматит, псориаз, себорейный кератоз, остроконечные кондиломы, атрофические заболевания вульвы (красный плоский лишай, склеротический лишай, крауроз), педикулез, чесотка, лейкоплакия [1].

Существуют дополнительные признаки, которые могут быть полезными в верификации диагноза. Так, например, изменения на коже и слизистой оболочке аногенитальной области свидетельствуют либо о токсической, либо о психогенной природе зуда. Наличие лихенизации характеризует длительное течение зуда без присоединения инфекции, а утолщение клитора и усиление кожного рисунка в области половых губ и внутренней поверхности бедер - аутоэротизм. Клинические принципы ирритации и рваные раны подразумевают самоповреждение без вторичного инфицирования при самонаказании как средство предотвращения полового акта. Пиогензация является частым осложнением расчесов, особенно на фоне сахарного диабета, что обусловливает необходимость проведения глюкозотолерантного теста даже в том случае, когда отсутствуют повышение уровня глюкозы в крови и глюкозоурия [17].

\section{Терапия аногенитального зуда у женщин}

В лечении аногенитального зуда первоочередной задачей является выявление основной причины: инфекционные агенты, воспалительные дерматозы или простое раздражение. В случае выявления первичного кожного заболевания следует проводить специальное ле- 
чение. Если установлено, что это связано с системными проблемами, аноректальным или генитальным расстройством, следует начать соответствующее лечение [15].

Особую сложность представляет зуд вульвы и перианальной области в случаях отсутствия установленной причины - идиопатический аногенитальный зуд. Общие мероприятия по предотвращению зуда включают устранение таких факторов, как пот, окклюзия, использование дополнительных средств во время гигиенических мероприятий, активное вытирание полотенцем после мытья. Нижнее белье должно быть просторным и состоять из натуральных тканей. В разрезе проблемы аногенитального зуда предпочтительнее использовать тампоны во время менструации и исключить использование гигиенических прокладок, в том числе для ежедневного использования. В качестве купирования зуда можно использовать холодные примочки. Основой лечения неспецифического зуда вульвы и ануса являются топические глюкокортикостероиды (ТГКС) [7]. Рекомендовано начинать лечение высокоактивными стероидами, такими как клобетазола пропионат 0,05\%, с последующим переходом на ТГКС из класса средней или легкой потенции. В тяжелых случаях используют введение пролонгированных ГКС непосредственно в очаг поражения. Альтернативой применения гормональных препаратов является использование топических ингибиторов кальциневрина (ТИК) такролимуса и пимекролимуса, особенно у женщин с дистрофическими заболеваниями вульвы в постменопаузе. В комплексе с противовоспалительными препаратами в терапии могут применяться местные анестетики (бензокаин, лидокаин и прилокаин), а также средства, содержащие капсаицин и доксепин $[18,19]$.

Системную терапию зуда, как правило, начинают с применения антигистаминных препаратов (АГП), однако они эффективны только в слу- чаях заболеваний аллергической природы. Имеются рекомендации о предпочтении использования АГП с седативным эффектом. В современной медицинской практике подобные рекомендации недопустимы, так как седативный эффект АГП старого поколения обусловлен формированием нефизиологического сна и развитием целого ряда нежелательных явлений (снижение когнитивной активности, нарушение сердечной проводимости, глаукома, острая задержка мочи и развитие тахифилаксии) [20]. С целью подавления центральных механизмов зуда могут использоваться антагонисты опиоидных рецепторов, ингибиторы обратного захвата серотонина, доксепин, антиконвульсанты и нейролептики. Высокой эффективностью обладают метод местной невральной блокады и введение ботулотоксина А в зону участков крупных нервов, обеспечивающих иннервацию кожи наружных половых органов [21].

\section{Заключение}

Аногенитальный зуд у женщин является распространенной проблемой полиэтиологичной природы. Вследствие особенностей локализации зудящего процесса эпидемиологические данные недостоверны, что обусловлено низкой обращаемостью пациенток к специалистам. Зачастую хроническое течение аногенитального зуда приводит к социальной и сексуальной дезадаптации женщин, оказывая выраженное влияние на качество жизни. Своевременное выявление первичных триггеров зуда и дифференциальная диагностика в значительной степени повышают вероятность быстрого достижения клинического эффекта в лечении такого сложного контингента пациентов. Следуя рекомендациям специалистов и используя современные методы местной и системной терапии заболеваний, сопровождающихся зудом, в настоящее время возможно оказать быструю помощь больным женщинам с достижением стабильных результатов.

\section{Список Аитературь}

1. W.I. van der Meijden, I, M. J. Boffa, W.A. ter Harmsel, G. Kirtschig, 4 F. M. Lewis, 5 M. Moyal-Barracco,6 G. S. Tiplica,7 J. Sherrard8 European guideline for the management of vulval conditions JEADV 2017, p. 1-17

2. Twycross R, Greaves MW, Handwerker H, et al. Itch: scratching more than the surface. QJM. 2003; 96: 7-26.

3. Stander S, Weisshaar E, Mettang T, et al. Clinical classification of itch: a position paper of the International Forum for the Study of Itch. Acta Derm Venereol. 2007; 87: 291-94.

4. Siddiqi S, Vijay V, Ward M, Mahendran R, Warren S. Pruritus ani. Ann R Coll Surs Engl. 2008; 90: 457-63.

5. Torgesson RR, Edwards L. Disease and disorders of the female genitalia. Fitzpatrick's dermatology in general medicine. 7th edition. New York: McGrawHill Medical; 2008.

6. Baver A, Rodiger C, Greif C et al. Vulvar dermatoses-irritant and allergic contact dermatitis of the vulva. Derm 2005; 210: 143.

7. Weichert GE. An approach to the treatment of anogenital pruritus. Dermatol Ther. 2004; 17: 129-33.

8. Gach JE, Seddon FH. Gluten-sensitive enteropathy associated with genital lichen simplex chronicus. J R Soc Med Sh Rep. 2010; 1: 43.

9. Cohen $A D$, Vander T, Medvendovsky E, Biton A Naimer S, Shaley R, et al. Neuropathic scrotal pruritus: anogenital pruritus is a symptom of lumbosacral radiculopathy. J A Acad Dermatol. 2005; 52 (1): 61-66.

10. Stewart KM. Clinical care of vulvar pruritus, with emphasis on one common cause, lichen simplex chronicus. Dermatol Clin 2010; 28: 669-80.

11. Potenzieri C, Undem BJ. Basic mechanisms of itch. Clin Exp Allergy. 2012; 42 (1): 8-19.

12. Катина М. А. Кожный зуд. Учебно-методическое пособие, Витебск: ВГМУ. 2014. С. 5-7.

13. Arican O. Pathophysiology, clinical presentation and management of pruritus // Turk derm-Archives of the Turkish Dermatology and Venereology. 2005. Vol. 39. P. 88-97.

14. Van Os-Medendorp H., Eland- de Kok P., Gypdonck M. et al. Prevalence and predictors of psychosocial morbidity in patients with chronic pruritic skin // Journal of European Academy of Dermatology and Venereology. 2006. Vol. 20. P. 810-817.

15. Lynch PJ. Lichen simplex chronicus (atopic/ neurodermatitis) of the anogenital region. Dermatol Ther. 2004; 17 (1): 8-19.

16. Lysy J, Sisstiery-Ittah M, Shmueli A, Strauss-Liviatan N, Mindrul V, Keret, Goldin E. Topical capsaicin - a novel and effective treatment for idiopathic intractable pruritus ani: a randomized, placebo controlled, crossover study. Gut. 2003; 52 (9): 1323-26.

17. Sonnex C. Genital allergy. Sex Transm Infect 2004; 80: 4-8.

18. Elmariah SB, Lerner EA. Topical therapy for pruritus. Semin Cutan Med Surg. 201 1; 30 (2): 118-26.

19. Biro T., Ko M. C., Bromm B. et al. How best to fight that nasty itch - from new insights into the neuroimmunological, neuroendocrine, and neurophysiological bases of pruritus to novel therapeutic approaches // Experimental Dermatolology. 2005. Vol. 14 (3). P. 225-240.

20. Перламутров Ю. Н. О^ьховская К. Б. ^япон А. О. Антигистаминные препараты в Аерматологической практике. Клиническая Аер матология и венерология 2018. № 2. С. 62-69.

21. Stewart KM. Clinical care of vulvar pruritus, with an emphasis on one common cause, lichen simplex chronicus. Dermatol Clin. 2010; 28 (4): 669-80. 